\title{
Timing of Infection and Development of Alternaria Diseases in the Canopy of Apple Trees
}

D. O. C. Harteveld and O. A. Akinsanmi, Centre for Plant Science, Queensland Alliance for Agriculture and Food Innovation; K. Chandra, Animal Science, Department of Agriculture, Fisheries \& Forestry; and A. Drenth, Centre for Plant Science, Queensland Alliance for Agriculture and Food Innovation, University of Queensland, Ecosciences Precinct, GPO Box 267, Brisbane, QLD 4001, Australia

\begin{abstract}
Harteveld, D. O. C., Akinsanmi, O. A., Chandra, K., and Drenth, A. 2014. Timing of infection and development of Alternaria diseases in the canopy of apple trees. Plant Dis. 98:401-408.

Alternaria leaf blotch and fruit spot of apple caused by Alternaria spp. cause annual losses to the Australian apple industry. Erratic control using protectant fungicides is often experienced and may be due to the lack of understanding of the timing of infection and epidemiology of the diseases. We found that Alternaria leaf blotch infection began about 20 days after bloom (DAB) and the highest disease incidence occurred from 70 to $110 \mathrm{DAB}$. Alternaria fruit spot infection occurred about 100 $\mathrm{DAB}$ in the orchard. Fruit inoculations in planta showed that there was

no specific susceptible stage of fruit. Leaves and fruit in the lower canopy of trees showed higher levels of leaf blotch and fruit spot incidence than those in the upper canopy and the incidence of leaf blotch in shoot leaves was higher than in spur leaves. Temperature, relative humidity, and rainfall affected leaf blotch and fruit spot incidence. The gained knowledge on the timing of infection and development of disease may aid in the development of more effective disease management strategies.
\end{abstract}

The Australian apple industry produces about 300,000 metric tons per annum (3). Diseases caused by Alternaria spp., Alternaria leaf blotch and fruit spot, cause significant losses. Alternaria leaf blotch is characterized by brown blotches ( \pm 2 to $10 \mathrm{~mm}$ in diameter) on the leaves that are often surrounded by a dark margin. Over time, the leaves turn yellow and abscise prematurely from the canopy (20). Alternaria fruit spot is characterized by slightly sunken, small ( $\pm 2 \mathrm{~mm}$ in diameter) brown spots, often surrounded by a black border (20). Leaf blotch and fruit spot mostly affect highvalue cultivars, such as 'Royal Gala', 'Fuji', 'Pink Lady', and 'Red Delicious' (9). Alternaria leaf blotch was first reported in the United States in 1924 (21) and has now been observed in applegrowing regions in Asia $(10,14,27,29)$, Europe $(1,18,24,36)$, Russia (7), and South America (22). Alternaria leaf blotch was first reported in Queensland in the 1990s and, thereafter, was observed in all apple-producing regions in Australia (9). In contrast to Alternaria leaf blotch, Alternaria fruit spot has only been reported from Japan in the 1950s (26) and Italy in 2003 (24). In Australia, Alternaria fruit spot was first reported in Queensland in 2002 but has now also been observed in New South Wales growing regions (9). Yield losses due to both diseases of up to $25 \%$ have occurred in Queensland and New South Wales, with diseased fruit downgraded to juicing, where grower returns are devalued by an average of $90 \%$. In addition to yield and quality losses of fruit, early defoliation also depletes the carbohydrate reserves in the plants, giving rise to poor productivity of the plants in the following season $(2,30)$.

The seasonal physiological stages of the apple season are (i) green tip, (ii) flowering or bloom, (iii) fruit development, (iv) harvest, and (v) dormancy (16). The timing of these stages in the orchard is used to time disease management strategies (16). In Australia, Alternaria leaf blotch and fruit spot symptoms become

Corresponding author: D. O. C. Harteveld,

E-mail: dalphy.harteveld@uqconnect.edu.au

Accepted for publication 1 October 2013.

http://dx.doi.org/10.1094/PDIS-06-13-0676-RE

(C) 2014 The American Phytopathological Society visible over summer (December to February) during the major period of fruit development.

The species of Alternaria causing leaf blotch and fruit spot is a source of confusion. For instance, multiple Alternaria spp. groups (Alternaria arborescens, A. tenuissima, and A. alternata) have been reported to cause both diseases in Italy (24). In Australia, four Alternaria spp. groups were reported to be associated with both diseases: A. arborescens, A. tenuissima/A. mali, A. alternata/A. tenuissima-intermediate, and $A$. longipes (8). In addition, $A$. mali $(4,26)$, also referred to as A. alternata apple pathotype $(12,14)$ or A. alternata f. sp. mali $(7,37)$, has been reported to cause leaf blotch in Japan (27), China (14), Korea (10), United States (4), Russia (7), Yugoslavia (1), Iran (29), Turkey (18), and Brazil (22) and fruit spot in Japan (27).

There is a paucity of information on the disease cycle of both diseases. Few studies have investigated features of the disease cycle of Alternaria leaf blotch and fruit spot and there is disparity in reports on the factors that contribute to conditions for infection $(5,27)$, disease development $(4,26)$, and epidemics $(6,31,33)$. Environmental conditions that enable infection and disease development vary among regions (33). In the United States, $5 \mathrm{~h}$ of leaf wetness and a temperature of $23.5^{\circ} \mathrm{C}$ were the optimum conditions for A. mali to initiate leaf infection (5) whereas, in Japan, optimum conditions for leaf infection occur at 28 to $30^{\circ} \mathrm{C}$ (27). Rainfall, relative humidity $(\mathrm{RH})$, leaf wetness, and temperature influence leaf blotch disease development $(5,13,27,32,40)$. In Australia, both diseases occur in warm, humid summer months but there is little information on what climatic factors are critical to the development of Alternaria leaf blotch and fruit spot in the orchard.

Infection of Alternaria spp. on apple leaves may also be influenced by variation in tree architecture, such as canopy density, leaf types, or spurriness habits. Spur leaves surround the flower buds from bud burst to full bloom (11). They are in close proximity to fruit and support the fruit more than shoot leaves, which grow on extending shoots around bloom stage $(11,38)$. It is unknown whether spur or shoot leaves are more susceptible to Alternaria spp. infection or whether the close proximity of spur leaves to developing fruit influences fruit spot infection. Therefore, an important question remains as to whether spur or shoot leaves are more susceptible to Alternaria spp. and whether the incidence of leaf blotch in the tree canopy influences the timing of fruit spot infection. 
It is not known whether primary infection occurs more frequently and is distributed on leaves and fruit in the lower canopy compared with those in the upper canopy. Anecdotal observations in Australian orchards suggest that leaf blotch incidence is higher in the lower part of the tree canopy, which is similar to the description of leaf blotch development in North Carolina in the United States (33). This pattern of progression suggests that the primary source of inoculum is from the ground or orchard floor from the crop residue under the tree canopy. If the inoculum on the orchard floor plays a significant role, then this is expected to be reflected in the distributions of infections of leaf and fruit in the canopy.

The expression of initial symptoms of Alternaria leaf blotch occurs from the flowering or bloom stage to 1 month after bloom in Japan (26) and the United States (4). There is a lack of rigorous testing of the time of infection and the incidence and severity of Alternaria leaf blotch in Australia. Symptoms of fruit spot are mainly observed at harvest and after storage $(9,24)$; however, in Australia, anecdotal reports indicate that fruit spots occur 6 to 8 weeks before harvest (9). There is no systematic study on the timing of Alternaria spp. infection on fruit.

Improvement in disease control depends on accurate information concerning the source of inoculum, time of infection, and environmental conditions conducive for disease development. Considering that different species groups of Alternaria have been found to cause either or both leaf blotch and fruit spot in Australia, it is important to determine the disease cycle of the causal agents in more detail. Therefore, the aims of this study were to (i) determine the timing of infection of Alternaria leaf blotch and fruit spot of apple, (ii) determine the growth stage when developing fruit is most susceptible to infection, (iii) test the hypothesis that the position of leaves and fruit in the canopy plays a significant role in Alternaria leaf blotch and fruit spot infection, and (iv) identify the most significant climatic factors influencing disease incidence of Alternaria leaf blotch and fruit spot in the field. Addressing these aims will allow for the development of improved disease management strategies.

\section{Materials and Methods}

Field site and trial design. Field trials were conducted at the Applethorpe Research Station $\left(28^{\circ} 36^{\prime} \mathrm{S}, 151^{\circ} 57^{\prime} \mathrm{E}\right)$ of the Department of Agriculture, Fisheries and Forestry (DAFF), Queensland, Australia, using mature experimental orchards ( $>10$ years old) of susceptible Royal Gala and 'FB22-47' apple in the 2010-11 and the 2011-12 seasons. Disease incidence and spatial distribution data were obtained from nine sample trees, representing three replicates of three trees per replicate per cultivar. The trees were spatially separated in the rows, with 10 to 15 buffer trees between sample trees. Fruit inoculation experiments were performed using trees randomly selected in the orchard.

Timing of infection and symptom expression of Alternaria leaf blotch disease. To examine the timing of Alternaria leaf blotch incidence in the tree canopy, leaf blotch incidence was monitored on each sample tree every 2 to 3 weeks from the beginning of spring at bloom until the end of the season, when the trees become dormant. Each time point of data collection was calculated as the days after bloom (DAB) using the date of full bloom of each cultivar. On each tree, 60 shoots randomly spread in the tree canopy were selected and the first 10 fully expanded leaves from the tip of each shoot were examined for Alternaria leaf blotch symp- toms. Disease incidence was recorded as percentage of leaves showing symptoms.

Potted trees of FB22-47 and Royal Gala were exposed routinely to natural infection under field conditions in the apple orchard for defined periods of time. The young potted trees were maintained in a glasshouse and pruned to obtain 4-week-old leaves for each exposure time. The trees were routinely fertilized and monitored for the presence of other pathogens, aphids, and mites. Only healthy potted trees free of diseases and pests were placed in the orchard. Three potted trees of each cultivar were placed under the canopy within the tree row in the orchard of FB22-47 for periods of 20 days. These periods coincided with five subsequent growth stages during fruit development, starting from 30 to 130 DAB during the 2010-11 and 2011-12 production seasons. At the end of each 20-day period, the trees were replaced by a new batch of three potted trees. After 20 days of field exposure, the number of leaves showing symptoms on each tree was recorded immediately as a percentage of the total leaves on each tree $\left(\mathrm{DI}_{0}\right)$. Then, the trees were incubated in a $>90 \% \mathrm{RH}$ chamber at $25^{\circ} \mathrm{C}$ for $48 \mathrm{~h}$. After incubation, the trees were placed in a glasshouse at $23 \pm 4^{\circ} \mathrm{C}$ and were monitored for further development of leaf blotch symptoms every 2 weeks for 8 weeks $\left(\mathrm{DI}_{2}-\mathrm{DI}_{8}\right)$. To confirm that the symptoms were caused by Alternaria spp., the causal agent of the leaf blotch symptoms was isolated, cultured, and identified morphologically, as described by Harteveld et al. (8), using a representative diseased leaf for each tree exposed.

Timing of infection and symptom expression of Alternaria fruit spot disease. To determine the timing of infection and expression of Alternaria fruit spot symptoms in the tree canopy in the apple orchard, three trials were performed using FB22-47 and Royal Gala: (i) field observation of fruit on sample trees exposed to natural infection in the orchard, (ii) fruit inoculation in planta in the orchard, and (iii) a detached fruit inoculation trial. In the natural infection trial, fruit spot incidence was monitored on each of the three sample trees per replicate per cultivar at fortnightly intervals from $40 \mathrm{DAB}$ until harvest at about $135 \mathrm{DAB}$. On each observation date, 150 fruit arbitrarily selected in the canopy of each tree were examined for fruit spot symptoms, and disease incidence was recorded as the percentage of fruit with symptoms.

The in planta and detached fruit inoculations were performed fortnightly during fruit development stage starting at approximately 40 DAB until harvest using four Alternaria spp. isolates (Table 1) associated with leaf blotch and fruit spot of apple in Australia (8). Each time, different fruit were inoculated for five inoculation periods. To determine the fruit maturity level at each inoculation date, three fruit per cultivar were examined for fruit diameter using a caliper and for sugar content using a refractometer. To obtain spore suspensions of the isolates, each isolate was grown on half-strength potato dextrose agar (PDA; Difco Laboratories Inc.), as previously described (8). Spore suspensions were obtained by flooding 7-day-old cultures with sterile water, and dislodging the spores using a scalpel prior to filtering through two layers of cheesecloth. The concentration of conidia was determined using a hemocytometer and was adjusted to $1 \times 10^{5}$ spores $/ \mathrm{ml}$ with sterile water. A drop of the surfactant Tween 80 (Sigma-Aldrich) was added to the spore suspension to obtain a better spread of spores on the inoculated surface. For the in planta fruit inoculation trials, three replicate fruit were used per isolate and a control using sterile water was included. Fruit in the middle of each tree canopy was

Table 1. Alternaria isolates used for routine inoculations of apple fruit in the 2010-11 and 2011-12 seasons

\begin{tabular}{lllc}
\hline Isolate $^{\mathbf{x}}$ & \multicolumn{1}{c}{ Species group $^{\mathbf{y}}$} & State of origin & Plant $^{\text {part }} \mathbf{z}$ \\
\hline BRIP 46550 & Alternaria alternatalA. tenuissima intermediate & Queensland & Fruit \\
BRIP 46492 & A. arborescens & Western Australia & Fruit \\
BRIP 46361 & A. tenuissima/A. mali & New South Wales & Leaf \\
BRIP 46455 & A. longipes & Western Australia & Leaf \\
\hline
\end{tabular}

${ }^{\mathrm{x}}$ Numbers represent the BRIP codes of the isolates as coded by the Queensland Plant Pathology Herbarium, Brisbane, Australia.

y Alternaria spp. group as identified in Harteveld et al. (11).

${ }^{z}$ Plant part where the isolate was initially obtained. 
inoculated using an air-pressure sprayer containing a spore suspension of each isolate and sprayed until run-off on one side of the fruit. Inoculated fruit were covered by clear polyethylene plastic bags with a self-adhesive seal containing wet cotton wool to maintain high humidity for $24 \mathrm{~h}$. Thereafter, a white paper bag was placed over the fruit to cover the fruit from natural infection. Fruit spot incidence was recorded fortnightly for 8 weeks.

In the detached fruit inoculation trial, fruit from the same five growth stages inoculated in the in planta trial were used. At each growth stage, 24 fruit of each cultivar were harvested from a tree in the orchard and kept in cold conditions on transit to the laboratory. In the laboratory, each fruit was rinsed in reverse-osmosis deionized water and air dried before spray inoculation as described above. Inoculated fruit and noninoculated fruit used as controls were kept in a closed box lined with wet paper towels to maintain high humidity and incubated at $25^{\circ} \mathrm{C}$ in darkness for $48 \mathrm{~h}$. Thereafter, the inoculated fruit were kept at ambient conditions $\left(22 \pm 2^{\circ} \mathrm{C}\right)$ and examined for fruit spot symptoms fortnightly for 8 weeks.

Spatial pattern of Alternaria leaf blotch in the tree canopy. Leaf blotch incidence was monitored on each sample tree as described above. In addition, each tree was divided into three canopy heights (lower, middle, and upper), each representing approximately one-third of the tree canopy height. A sampling unit consisted of 20 leaves (10 spur leaves and 10 shoot leaves). At each canopy height (lower, middle, and upper), 10 sampling units were examined for Alternaria leaf blotch and disease incidence was recorded as the number of leaves showing symptoms of 10 leaves per leaf type.

Spatial pattern of Alternaria fruit spot in the tree canopy. Fruit spot incidence was monitored at fortnightly intervals from 40 until $135 \mathrm{DAB}$, as described above. In addition, on each observation date, 50 fruit, arbitrarily selected, were examined at each tree canopy height (lower, middle, and upper) and disease incidence was recorded as the percentage of fruit with fruit spot symptoms.

The influence of climatic factors on Alternaria leaf blotch and fruit spot disease in the field. Weather data were recorded from July 2010 until July 2012, including daily minimum and maximum temperature, daily mean $\mathrm{RH}$, and daily rainfall. The weather data were obtained from the Bureau of Meteorology, Australia, Applethorpe station 041175, which was located at the DAFF Applethorpe Research Station was used for the studies. All weather data for each climatic factor and their combinations were analyzed for their influence on disease incidence.

Data analysis. Disease incidence data for Alternaria leaf blotch and fruit spot were analyzed separately using GenStat (14th edition; VSN International Ltd.). To determine whether there was a significant difference between disease incidence at DAB, different canopy heights, and leaf types, a repeated measures analysis of variance (ANOVA) was performed for cultivar and season. Canopy height and leaf type were treated as fixed effects whereas tree, canopy height within tree, and leaf type within canopy height within tree were included as blocking effects. The disease incidence measured at $0,20,33,67,88$, and 106 DAB in the 2010-11 season and at $0,14,36,49,71,97,108,128$, and $141 \mathrm{DAB}$ in the 2011-12 season was used as the time factor. To test the relationships between the variables, pairwise comparisons were performed for all significant interactions using Fisher's protected least significant difference test.

Disease incidence data were further compared using the area under disease progress curve (AUDPC; 15). AUDPC data were square root transformed to stabilize variance. An additional ANOVA was performed using the AUDPC data to detect significance of interactions in disease incidence among canopy heights and between leaf types.

To identify the most significant climatic factor influencing leaf blotch and fruit spot incidence, the averages of each climatic factor-minimum and maximum temperature, daily rainfall and $\mathrm{RH}$, cumulative rainfall, and number of rainy days - were calculated for the periods between consecutive data collection dates. For the first collection date of each season, the data of the climatic factors over the preceding 2 weeks were used. To measure the change in disease incidence during each period, the difference in the disease incidence between consecutive collection dates was used in the analysis. All subset regression analysis based on a generalized linear model with normal distribution was performed to determine the best-fit model of the climatic factors on disease incidences. The regression model was evaluated based on the adjusted coefficient of determination $\left(R^{2}\right)$.

\section{Results}

Timing of infection and symptom expression of Alternaria leaf blotch disease. Full bloom occurred on 7 October 2010 and 3 October 2011 on Royal Gala and on 11 October 2010 and 6 October 2011 on FB22-47. On mature apple trees in the orchard, Alternaria leaf blotch symptoms were first observed at approximately 40 $\mathrm{DAB}$ on spur and shoot leaves in both cultivars (Fig. 1). In the 2010-11 season, initial disease incidence was about 5\% in FB2247 and $2 \%$ in Royal Gala whereas, in the 2011-12 season, it was $<0.2 \%$ in both cultivars (data not shown). In the 2010-11 season, the highest leaf blotch incidence was $41 \%$ at 125 DAB in FB22-47 and $25 \%$ at 110 DAB in Royal Gala whereas, in the 2011-12 season, the highest incidence of $44 \%$ in FB22-47 and $16 \%$ in Royal Gala was observed after harvest at 150 DAB. In both seasons and cultivars, extensive defoliation started after the highest disease incidence and continued until tree dormancy, giving rise to reduced disease incidence.

Initial symptoms were observed around the same time in both seasons but further disease increase in the 2011-12 season took place about 30 days later than in the 2010-11 season (Fig. 1). This delay in disease progress corresponds to a lower mean $\mathrm{RH}$ (55 to $65 \%$ ) for that period than in the 2010-11 season, where a higher $\mathrm{RH}$ (70 to $80 \%$ ) was observed for the same period. At approximately 90 DAB in the 2011-12 season, a storm event occurred which caused significant defoliation of trees, resulting in a temporary plateau in disease incidence (Fig. 1).

Results of the sequential exposure of potted trees to natural infection within the five growth periods showed that the most infections occurred at 70 to 90 and 90 to 110 DAB (Fig. 2). At 30 to 50 and 50 to $70 \mathrm{DAB}$, leaf blotch symptoms were consistently absent in both seasons and cultivars on the potted trees (Fig. 2). Leaf blotch incidence was significantly higher in Royal Gala than in FB22-47. Royal Gala had a mean $\mathrm{DI}_{0}$ of 30 and $7 \%$ in the 2010 11 and 2011-12 seasons, respectively, compared with FB22-47 having a mean $\mathrm{DI}_{0}$ of 7 and 3\% for FB22-47 in the 2010-11 and 2011-12 seasons, respectively. Leaf blotch incidence was significantly higher in the 2010-11 than the 2011-12 season. Although the leaf blotch incidence at $\mathrm{DI}_{2}$ was generally higher than at $\mathrm{DI}_{0}$, it was only significantly $(P=0.05)$ higher in FB22-47 at 90 to 110 DAB in the 2010-11 season (Fig. 2). Leaf blotch incidence at 110 to $130 \mathrm{DAB}$ was inconsistent between seasons and cultivars (Fig. 2). Leaf blotch incidences of the plants incubated for 8 weeks in the glasshouse were the same as when incubated for 2 weeks, indicating no further disease developed in the glasshouse 2 weeks after incubation.

Timing of infection and symptom expression of Alternaria fruit spot disease. Under natural field conditions, Alternaria fruit spot was first observed at 110 DAB in FB22-47 in the 2010-11 season and the fruit spot incidence (DI) remained low (at $0.4 \%$ ) from 110 DAB till harvest (Fig. 3). In the 2010-11 season in Royal Gala, fruit spot symptoms were first observed at $115 \mathrm{DAB}$, with initial disease incidence of $0.7 \%$, and the highest fruit spot incidence was $1.7 \%$ at $130 \mathrm{DAB}$, just before harvest (Fig. 3). In the 2011-12 season, no Alternaria fruit spot symptoms were observed in either cultivar.

The results of the in planta fruit inoculations showed that, among the four isolates, only BRIP 46361 (A. tenuissima/A. mali) and BRIP 46550 (A. alternata/A. tenuissima intermediate) caused fruit spot on Royal Gala (Table 2). No fruit spot symptoms developed in FB22-47 (data not shown). In Royal Gala, isolate BRIP 46361 caused fruit spot at all growth stages in both seasons and 
isolate BRIP 46550 caused fruit spot only on fruit inoculated at 40 and 55 DAB in the 2010-11 season (Table 2). Fruit spot symptoms were observed 2 weeks after inoculation. In both seasons, unlike under the natural field conditions, size and sugar content as measures of fruit maturity or growth stage did not influence the infection on the inoculated fruit. No fruit symptoms were observed in the detached fruit inoculation trial.

Spatial pattern of Alternaria leaf blotch in the tree canopy. Levels of Alternaria leaf blotch incidence varied significantly $(P<$ 0.001 ) among different canopy heights, leaf types, and their interactions with the cultivars (Table 3 ). Leaf blotch incidence was significantly higher in the lower canopy than in the upper canopy level (Table 4). Shoot leaves showed significantly higher disease incidence than spur leaves in both cultivars, except in FB22-47 in the 2010-11 season (Table 4). However, there was a difference in the incidences in the leaf types between cultivars. Disease incidence was almost double in the shoot leaves than in the spur leaves in Royal Gala but there was little difference among the leaf types in FB22-47 (Table 4). Within canopy height, no significant effect of leaf type was observed (Table 3 ). The three-way interaction of canopy height, leaf type, and DAB was significant $(P=0.015$ and $0.018)$ in FB22-47 in both seasons but was not significant $(P=$ 0.22 and 0.21 ) in Royal Gala. In the 2010-11 season, defoliation was first observed in spur leaves in the lower canopy after 115 DAB compared with after 125 DAB for the other canopy heights and for shoot leaves in FB22-47 (Fig. 1A). This was also observed in Royal Gala during the 2010-11 season, where defoliation of the spur leaves of the lower canopy height was about 20 days earlier (approximately $90 \mathrm{DAB}$ ) than defoliation in the other heights (Fig. 1C).

Spatial pattern of Alternaria fruit spot in the tree canopy. Fruit spot symptoms were mostly observed in the lower canopy (Fig. 4). In the 2010-11 season, fruit spot was first observed in Royal Gala at 115 DAB at the lower canopy height of the trees, with a mean initial disease incidence of $2.2 \%$ (data not shown) which resulted in $0.7 \%$ at the whole-tree level (Fig. 3). At 130 $\mathrm{DAB}$, the final fruit spot incidence was $3.3 \%$ in the lower, $1.6 \%$ in the middle, and $0.2 \%$ in the upper canopy (Fig. 4). In FB22-47, fruit spot was observed in the tree canopy at $110 \mathrm{DAB}$ and incidence stayed the same until harvest, with a mean of $0.6 \%$ in the lower and $0.6 \%$ in the middle canopy (Fig. 4). In the 2011-12 season, fruit spot was not observed on either cultivar.

The influence of climatic factors on Alternaria leaf blotch and fruit spot disease in the field. The most significant single climatic factor affecting leaf blotch and fruit spot disease incidence was minimum temperature, which explained $23 \%$ of the variability in leaf blotch incidence and $20 \%$ of the variability in fruit spot incidence (Table 5). For leaf blotch incidence, the adjusted $R^{2}$ improved to $45 \%$ when RH and cumulative amount of rain were included (Table 5). For fruit spot incidence, the greatest amount of

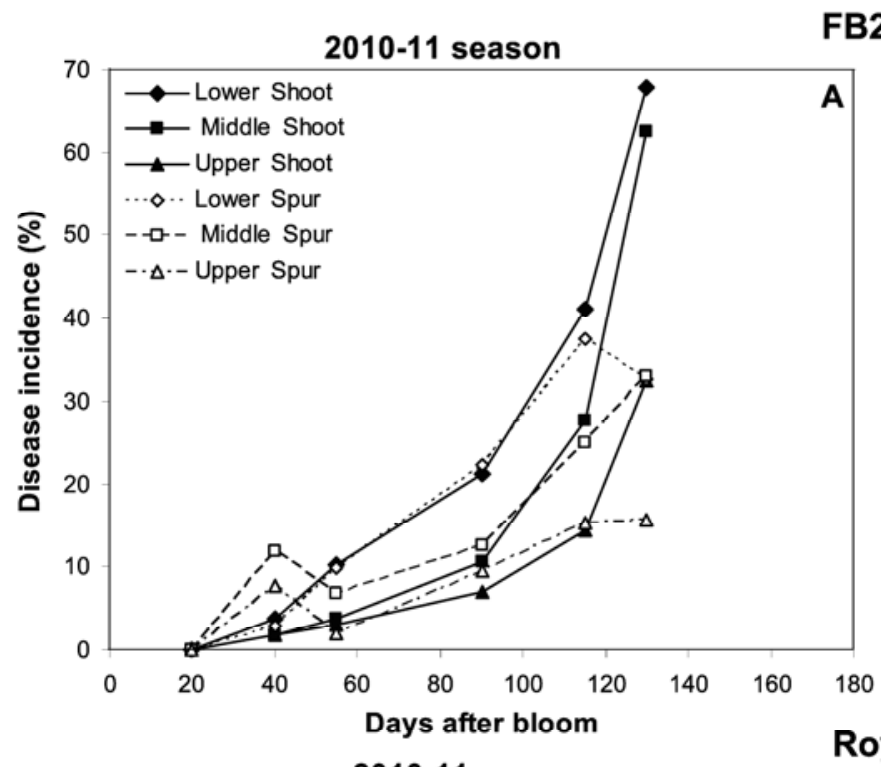

FB22-47

2011-12 season
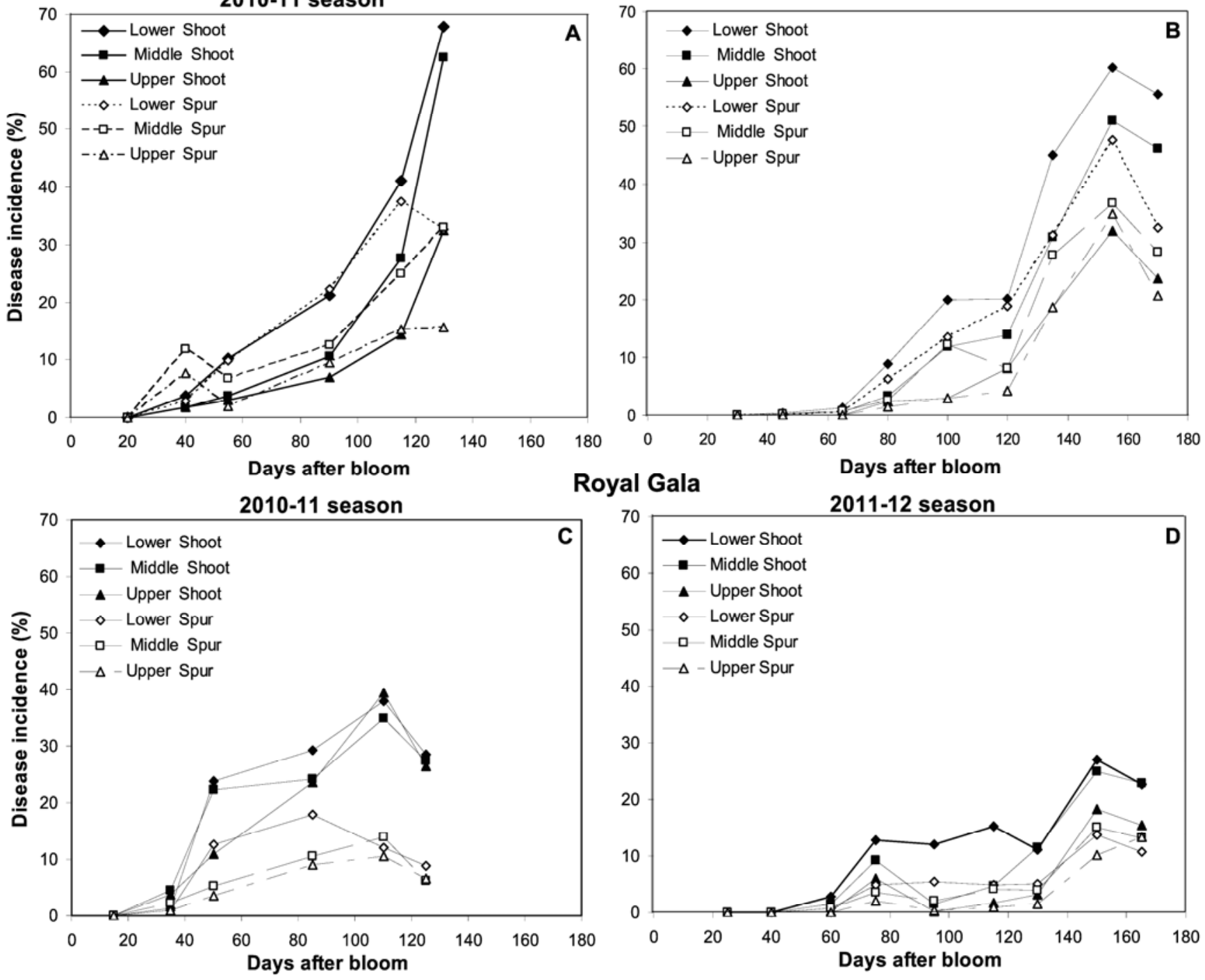

Fig. 1. Incidence of Alternaria leaf blotch in spur and shoot leaves in the lower, middle, and upper canopy height of apple trees of A and B, 'FB22-47' and C and D, 'Royal Gala' in the $\mathbf{A}$ and $\mathbf{C}, 2010-11$ and $\mathbf{B}$ and $\mathbf{D}, 2011-12$ production seasons. 
variance was explained when maximum temperature and mean daily rainfall were included in the model, explaining $32 \%$ of the variance (Table 5).

\section{Discussion}

In apple orchards located in Queensland, Australia, leaf blotch infection occurred 15 to $20 \mathrm{DAB}$, because symptoms were first detected about $40 \mathrm{DAB}$ and the time from inoculum exposure to symptom expression was found to be $<2$ weeks. Alternaria fruit spot infection occurred between 95 to $110 \mathrm{DAB}$, because symptoms were observed in the orchard 110 to $130 \mathrm{DAB}$, about 2 to 3 weeks before harvest, and the period from exposure to development of symptoms was $<2$ weeks. The highest leaf blotch incidence occurred between 70 to $110 \mathrm{DAB}$, thus indicating the time in the season with the most conducive conditions for infection. Temperature and rain were identified as the most significant climatic factors influencing leaf and fruit spot disease. Leaf blotch and fruit spot disease incidence was higher in the lower canopy than the middle and upper canopy, indicating that inoculum from the orchard floor or the microclimate in the lower canopy may play an important role in the disease cycle.

The timing of the first Alternaria leaf blotch symptoms in the orchard was about $40 \mathrm{DAB}$, which is about a month after bloom and was previously reported in North Carolina (4). This is different from a report from Japan, where symptoms were first detected after bloom (26). The difference between regions, including weather, pathogen population, and different cultivars and rootstocks, may explain this variation. This is the first study to investigate the timing of infection Alternaria fruit spot of apple. The timing of Alternaria fruit spot infection in the orchard was around $100 \mathrm{DAB}$, about a month before harvest. However, when using in planta artificial inoculations, the fruit were susceptible to Alternaria spp. infection at all stages during fruit development. This is in line with inoculation studies using Alternaria isolates pathogenic to manda-

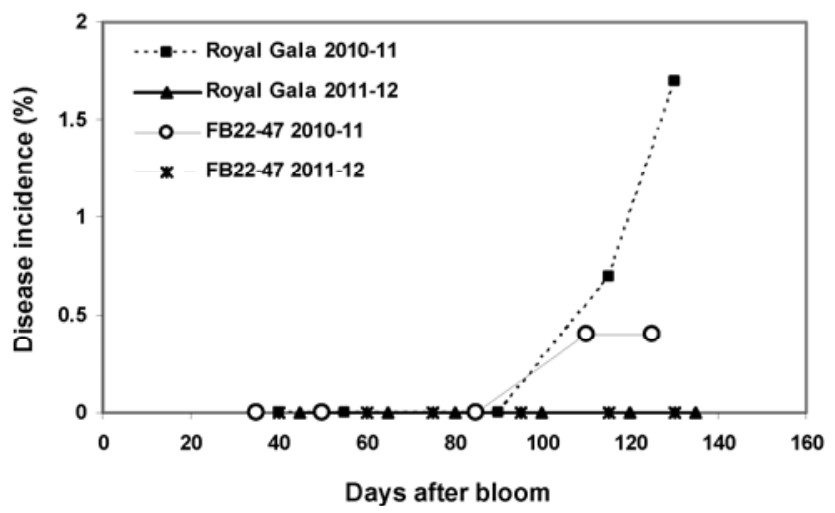

Fig. 3. Incidence of Alternaria fruit spot in apple trees of 'Royal Gala' and 'FB22-47' in the 2010-11 and 2011-12 production season.

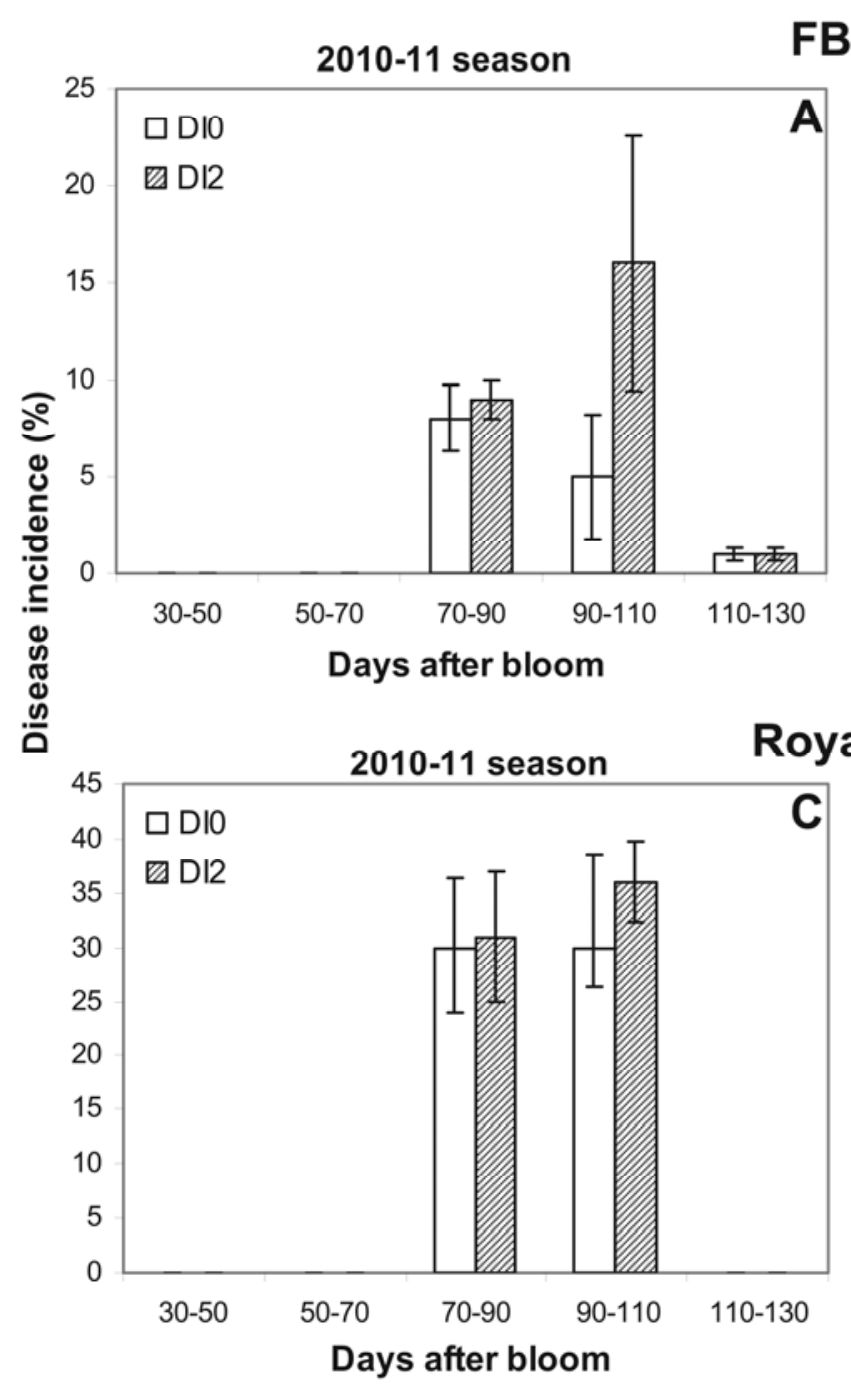

FB22-47
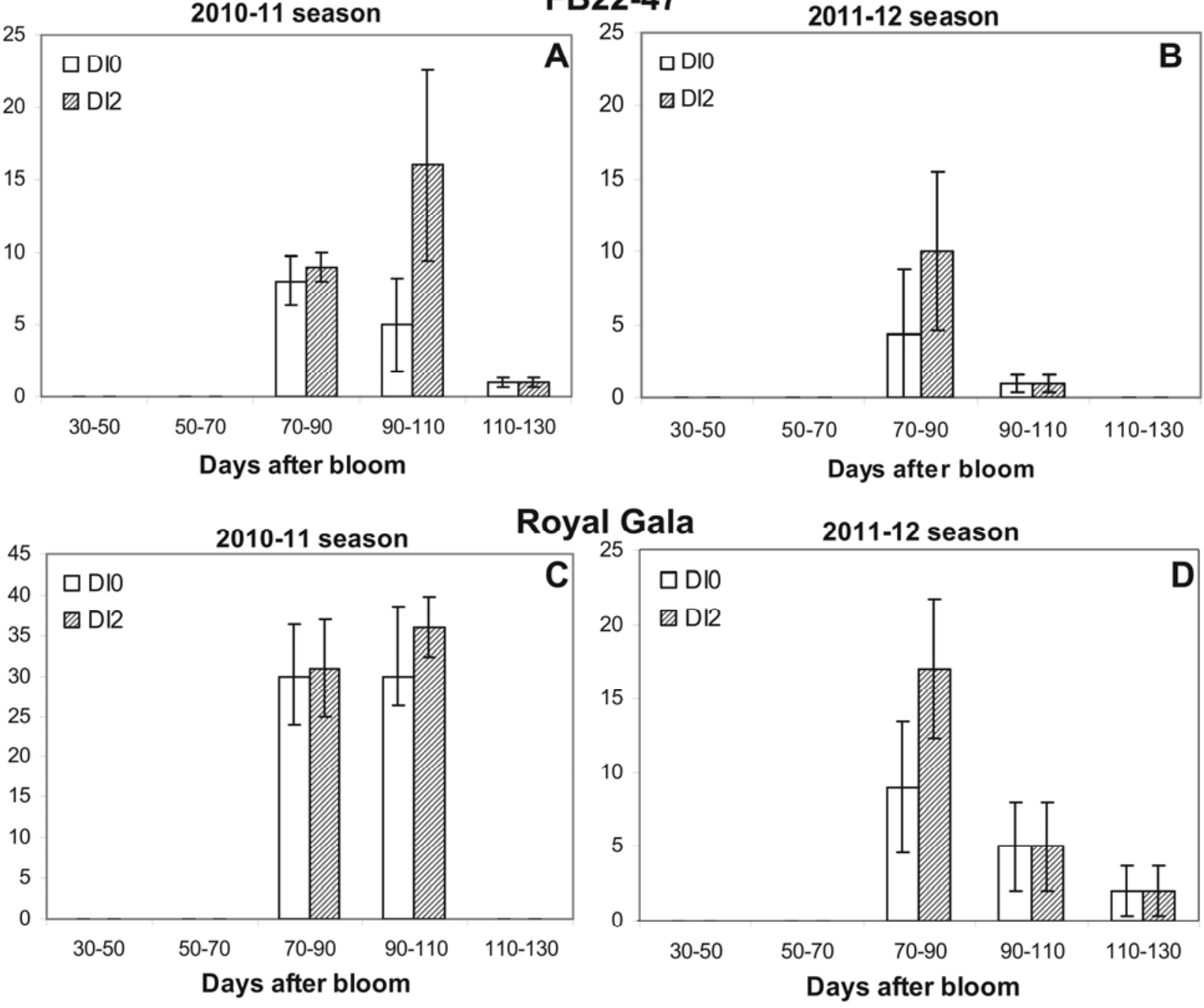

Fig. 2. Incidence of Alternaria leaf blotch in potted trees of $\mathbf{A}$ and B, 'FB22-47' and $\mathbf{C}$ and $\mathbf{D}$, 'Royal Gala' that were sequentially exposed to natural infection in the orchard in the $\mathbf{A}$ and $\mathbf{C}, 2010-11$ and $\mathbf{B}$ and $\mathbf{D}, 2011-12$ seasons. DI0 is disease incidence after exposure and DI2 is disease incidence 2 weeks after incubation in the glasshouse. Lines on bars indicate standard error. 
rin fruit $(17,35)$ and Japanese pear fruit $(25)$. Therefore, our observations in the orchard may indicate the time of more conducive environmental conditions during the season rather than susceptibility of the fruit.

This study showed that leaf blotch and fruit spot infection were not evenly distributed in the canopy. The lower canopy height had higher disease incidence than the middle and upper canopy heights, which was also observed in North Carolina (33). This indicates that the lower canopy was either a more conducive microclimate for infection or is exposed to higher levels of inoculum. Inoculum gravitating down to the lower canopy or splash dispersal of Alternaria spp. from the orchard floor may have contributed to a higher level of inoculum in the lower canopy because leaf debris on the orchard floor has been reported as a main source of Alternaria spp. inoculum in apple orchards $(6,28)$. Alternaria leaf blotch and fruit spot symptoms were observed at all canopy levels from initiation of disease expression, which indicated that wind in addition to splash dispersal may serve as an important mode of dispersal. Generally, Alternaria spp. are dispersed by wind but cases of rain splash have been reported on other crops (23). Further research is needed to investigate leaf debris on the orchard floor as a source of Alternaria spp. inoculum and the importance of splash dispersal of Alternaria spp. causing Alternaria leaf blotch and fruit spot of apple.

Both spur and shoot leaf types were susceptible to Alternaria spp. There was significant variation in disease incidence between the two leaf types between cultivars. This variation is in line with differences in the susceptibility and canopy architecture between the two cultivars. FB22-47 may be subject to a higher disease risk, because spur leaves were more exposed in this cultivar and showed higher incidence than in Royal Gala. Spur leaves play an important role as the primary carbohydrate support for fruit development (38). Therefore, diseased spur leaves may affect the development of fruit, giving rise to smaller fruit and, thus, lower yield. Another role of the spur leaves in the disease cycle of the Alternaria spp. may occur because spur leaves at the lower canopy height dropped more readily from the trees first in the 2010-11 season. Alternaria spp. grow and sporulate well in leaf debris (23); therefore, this premature drop may have contributed to increased levels of inoculum and increased leaf and fruit infection in the orchard between 90 and $110 \mathrm{DAB}$.

In contrast to leaf blotch, fruit spot disease incidence in the orchards was higher in Royal Gala than in FB22-47 and, using artificial inoculation, fruit spot symptoms only developed in Royal Gala. Therefore, FB22-47 may be less susceptible to fruit spot. The skin surface of the FB22-47 fruit is smoother and shinier than that of Royal Gala fruit; thus, the cuticle thickness or cuticular wax of the fruit may influence Alternaria spp. infection (19,39). Further studies should include ultrastructural examination to determine the infection process of the Alternaria spp. affecting apple fruit and test whether cytological variation in apple fruit skin can distinguish cultivars for their susceptibility to fruit spot.

Our study showed that temperature, $\mathrm{RH}$, and rainfall affected leaf blotch and fruit spot incidence. These three factors were also reported to play an important role on the leaf blotch dynamics in apple orchards in Korea (40) and have been demonstrated to affect Alternaria diseases on citrus and Japanese pear $(25,34)$. In citrus, duration of leaf wetness was an important factor (34), which should be considered in further studies on the epidemiology and forecasting of Alternaria leaf blotch of apple. The most significant factor influencing leaf blotch and fruit spot was temperatures below $20^{\circ} \mathrm{C}$. Higher temperatures $\left(>20^{\circ} \mathrm{C}\right)$ have been reported to induce Alternaria spp. infection in several studies $(5,27,32)$. Fruit symptoms resulting from exposure to natural infection were found

Table 3. Repeated measures analysis of variance of Alternaria leaf blotch disease incidence $(\%)$ on different leaf types at different canopy heights recorded from bloom to harvest growth stages in 'Royal Gala' and 'FB2247' apple trees ${ }^{\mathrm{Z}}$

\begin{tabular}{lcrr}
\hline Source of variation & df & VR & \multicolumn{1}{c}{$\boldsymbol{F}$} \\
\hline Cultivar & 1 & 2.31 & 0.148 \\
Canopy height & 2 & 45.41 & $<0.001$ \\
Canopy height $\times$ cultivar & 2 & 15.38 & $<0.001$ \\
Leaf type & 1 & 105.26 & $<0.001$ \\
Canopy height $\times$ leaf type & 2 & 0.65 & 0.527 \\
Leaf type $\times$ cultivar & 1 & 31.09 & $<0.001$ \\
Canopy height $\times$ leaf type $\times$ cultivar & 2 & 1.42 & 0.252 \\
\hline
\end{tabular}

${ }^{\mathrm{z}}$ Abbreviations: df indicates degrees of freedom, VR indicates variance ratio, and $F$ indicates probability Fisher's value.

Table 4. Area under disease progress curve values for the Alternaria leaf blotch disease incidence in different canopy heights (lower, middle, and upper, mixed leaf types) and leaf types (shoot and spur) of two apple cultivars (Royal Gala and FB22-47) in the 2010-11 and 2011-12 productions seasons ${ }^{2}$

\begin{tabular}{lcclll}
\hline & \multicolumn{2}{c}{ 2010-11 season } & & \multicolumn{2}{c}{ 2011-12 season } \\
\cline { 2 - 3 } \cline { 5 - 6 } Plant part & Royal Gala & FB22-47 & & Royal Gala & FB22-47 \\
\hline Canopy height & & & & & \\
Lower & $10.52 \mathrm{a}$ & $13.98 \mathrm{a}$ & & $7.83 \mathrm{a}$ & $13.50 \mathrm{a}$ \\
Middle & $9.40 \mathrm{ab}$ & $11.83 \mathrm{~b}$ & & $6.31 \mathrm{~b}$ & $11.16 \mathrm{~b}$ \\
$\quad$ Top & $8.30 \mathrm{~b}$ & $8.53 \mathrm{c}$ & & $4.05 \mathrm{c}$ & $8.10 \mathrm{c}$ \\
Leaf type & & & & & \\
$\quad$ Shoot & $12.06 \mathrm{a}$ & $11.69 \mathrm{a}$ & & $7.42 \mathrm{a}$ & $11.60 \mathrm{a}$ \\
Spur & $6.75 \mathrm{~b}$ & $11.20 \mathrm{a}$ & & $4.71 \mathrm{~b}$ & $10.23 \mathrm{~b}$ \\
\hline
\end{tabular}

${ }^{\mathrm{z}}$ Values in for each plant part section in each column followed by the same letter are not significantly different at $P=0.05$, according to Fisher's protected least significant differences.

Table 2. Fruit symptom development on apple fruit of 'Royal Gala' in planta inoculated with four Alternaria isolates at different days after bloom (DAB) in the 2010-11 and the 2011-12 production seasons

\begin{tabular}{|c|c|c|c|c|c|c|}
\hline \multirow[b]{2}{*}{ Season, DAB } & \multirow[b]{2}{*}{ Size $(\mathbf{m m})^{y}$} & \multirow[b]{2}{*}{ Sugar $\left({ }^{\circ} \text { Brix }\right)^{\mathbf{z}}$} & \multicolumn{4}{|c|}{ Isolate } \\
\hline & & & 46550 & 46492 & 46361 & 46455 \\
\hline \multicolumn{7}{|l|}{ 2010-11 } \\
\hline $35-40$ & $30 \pm 1$ & $5.5 \pm 0.5$ & Yes & No & Yes & No \\
\hline $50-55$ & $32 \pm 2$ & $7.0 \pm 0.5$ & Yes & No & Yes & No \\
\hline $85-90$ & $56 \pm 2$ & $8.5 \pm 0.0$ & No & No & Yes & No \\
\hline $110-115$ & $68 \pm 1$ & $9.0 \pm 0.5$ & No & No & Yes & No \\
\hline $125-130$ & $67 \pm 1$ & $10.0 \pm 0.5$ & No & No & Yes & No \\
\hline \multicolumn{7}{|l|}{ 2011-12 } \\
\hline $40-45$ & $26 \pm 1$ & $7.5 \pm 0.5$ & No & No & Yes & No \\
\hline $60-65$ & $43 \pm 1$ & $9.0 \pm 0.0$ & No & No & Yes & No \\
\hline $75-80$ & $53 \pm 0$ & $9.5 \pm 0.0$ & No & No & Yes & No \\
\hline $95-100$ & $63 \pm 5$ & $11.5 \pm 0.5$ & No & No & Yes & No \\
\hline $115-120$ & $73 \pm 2$ & $10.5 \pm 0.5$ & No & No & Yes & No \\
\hline $130-135$ & $71 \pm 3$ & $15.0 \pm 0.5$ & No & No & Yes & No \\
\hline
\end{tabular}

${ }^{\mathrm{y}}$ Mean fruit diameter $(n=3)$.

${ }^{z}$ Sugar content of the fruit $(n=3)$. 
in the orchard about 110 DAB and only in the 2010-11 season. This is in line with higher rainfall and higher RH preceding this time than in other months and compared with the weather during the 2011-12 season, indicating the requirement of these climatic factors for fruit spot infection. The requirement of moisture in addition to temperature to initiate Alternaria spp. infection on apple leaves has been demonstrated previously (26). Hence, in planta fruit inoculations using moist cotton wool to maintain high RH showed fruit spot symptom development at every fruit stage, showing the importance of this climatic factor. Further studies should investigate the influence of temperature, rainfall, and $\mathrm{RH}$ on release of conidia and infection of apple leaves and fruit by Alternaria spp. in more detail.

Fruit were inoculated with four isolates of Alternaria; however, only two isolates, BRIP 46361 of the species group A. tenuissima/A. mali and BRIP 46550 of the species group A. alternata/A. tenuissima, caused fruit symptoms. This is in congruence with Harteveld et al. (8), who reported that these species groups were more related to fruit disease than the isolates from the other species groups, A. arborescens and A. longipes.

Based on the results of this study, we can conclude (i) the timing of infection of Alternaria spp. in the field is about 20 DAB on leaves and about $100 \mathrm{DAB}$ on fruit; (ii) the lower canopy has higher disease incidence than the upper canopy; (iii) disease incidence in shoot leaves is higher than spur leaves; and (iv) temperature, $\mathrm{RH}$, and rainfall influence leaf blotch and fruit spot incidence in the field. These results have practical implications for the timing of control measures to prevent leaf blotch and fruit spot infection. Application of control measures that will reduce initial inoculum density may reduce leaf blotch infections. Leaf blotch incidence should be monitored and, if disease incidence exceeds a certain threshold at 90 DAB (January), a fungicide application may need to be applied to reduce available inoculum in the field and prevent

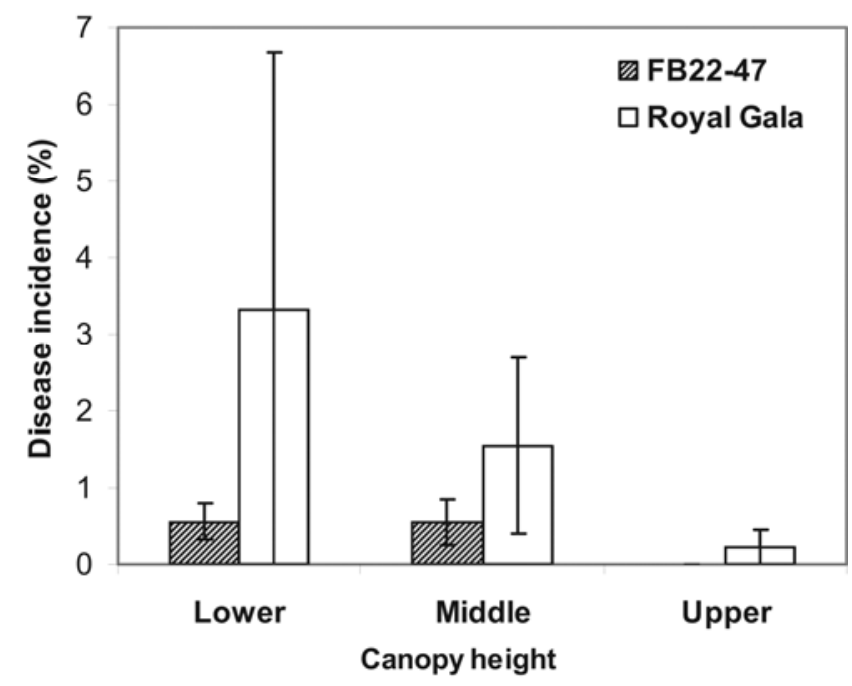

Fig. 4. Incidence of Alternaria fruit spot of apple fruit in the lower, middle, and upper canopy height of trees of 'FB22-47' and 'Royal Gala' at 130 days after bloom in the 2010-11 production season. Lines on bars indicate standard error. fruit spot infection. In addition, to reduce inoculum and disease incidence at lower canopy heights, fallen diseased leaves should be removed or degraded more rapidly through the application of urea or mulched prior to the production season. These management suggestions are currently being tested for their efficacy to reduce Alternaria leaf blotch and fruit spot in Australian orchards.

\section{Acknowledgments}

This work was funded by the Horticulture Australia Limited (Project AP06007) and levies from apple and pear growers. We thank the DAFF Applethorpe Research Station for providing the orchards, A. McWaters and S. Dullahide for their assistance at the research station, and A. K. Miles for critically reviewing the manuscript.

\section{Literature Cited}

1. Bulajic, A., Filajdic, N., Babovic, M., and Sutton, T. B. 1996. First report of Alternaria mali on apples in Yugoslavia. Plant Dis. 80:709.

2. Cordes, D. 1987. Vegetative and generative behaviour of apple trees after defoliation. Erwerbsobstbau 29:245-249.

3. FAOSTAT. 2011. World production by commodity for 2011. Food and Agriculture Organisation of the United Nations.

4. Filajdic, N., and Sutton, T. B. 1991. Identification and distribution of Alternaria mali on apples in North Carolina and susceptibility of different varieties of apples to Alternaria blotch. Plant Dis. 75:1045-1048.

5. Filajdic, N., and Sutton, T. B. 1992. Influence of temperature and wetness duration on infection of apple leaves and virulence of different isolates of Alternaria mali. Phytopathology 82:1279-1283.

6. Filajdic, N., and Sutton, T. B. 1995 . Overwintering of Alternaria mali, the causal agent of Alternaria blotch of apple. Plant Dis. 79:695-698.

7. Gagkaeva, T. Y., and Levitin, M. M. 2000. Identification of the pathogen causing leaf spots on apple trees in Krasnodar province orchards. Mikol. Fitopatol. 34:58.

8. Harteveld, D. O. C., Akinsanmi, O. A., and Drenth, A. 2013. Multiple Alternaria species groups are associated with leaf blotch and fruit spot diseases of apple in Australia. Plant Pathol. 62:289-297.

9. Horlock, C. M. 2006. Management of Alternaria leaf and fruit spot in apples. Final Report Project AP02011. Horticulture Australia Limited, Sydney, New South Wales, Australia.

10. Hwang, B. K., Yun, J. H., and Kim, Z. S. 1987. Geographic variation of esterase isozymes in populations of Alternaria mali on apple leaves. J. Phytopathol. 119:225-231.

11. Jackson, J. E. 2003. Biology of Apples and Pears. University of Cambridge Press, Cambridge.

12. Johnson, R. D., Johnson, L., Kohmoto, K., Otani, H., Lane, C. R., and Kodama, M. 2000. A polymerase chain reaction-based method to specifically detect Alternaria alternata apple pathotype (A. mali), the causal agent of Alternaria blotch of apple. Phytopathology 90:973-976.

13. Kim, C. H., Cho, W. D., and Kim, S. C. 1986. An empirical model for forecasting Alternaria leaf spot in apple. Korean J. Plant Prot. 25:221-228.

14. Li, Y., Aldwinckle, H. S., Sutton, T., Tsuge, T., Kang, G., Cong, P., and Cheng, Z. 2013. Interactions of apple and the Alternaria alternata apple pathotype. Crit. Rev. Plant Sci. 32:141-150.

15. Madden, L. V., Hughes, G., and Bosch, F. v. d. 2007. Temporal analysis I: quantifying and comparing epidemics. Pages 106-108 in: The Study of Plant Disease Epidemics. American Phytopathological Society, St. Paul, MN.

16. Mooney, A., Wilk, P., and Dodds, K. 2012. Apples-pests and growing periods. Page 28 in: Orchard Plant Protection Guide for Deciduous Fruits in NSW 2012-13, vol. 22. Department of Primary Industries, Orange, NSW, Australia

17. Nemsa, I., Hernandez, M. A., Lacasa, A., Porras, I., Garcia-Lidon, A., Cifuentes, D., Bouzid, S., Ortuno, A., and Del Rio, J. A. 2012. Pathogenicity of Alternaria alternata on fruits and leaves of 'Fortune' mandarin (Citrus clementina $\times$ Citrus tangerina). Can. J. Plant Pathol. 34:195-202.

18. Ozgonen, H., and Karaca, G. 2006. First report of Alternaria mali causing necrotic leaf spot of apples in Turkey. Plant Pathol. 55:578.

Table 5. Probabilities and the adjusted coefficient of determination for the most significant effects of climatic factors on Alternaria leaf blotch and fruit spot disease incidence

\begin{tabular}{|c|c|c|c|c|c|c|c|}
\hline Disease, $n^{\mathrm{z}}$ & $\begin{array}{c}\text { Minimum } \\
\text { temperature }\left({ }^{\circ} \mathrm{C}\right)\end{array}$ & $\begin{array}{c}\text { Maximum } \\
\text { temperature }\left({ }^{\circ} \mathrm{C}\right)\end{array}$ & $\begin{array}{c}\text { Mean daily } \\
\text { rainfall }(\mathbf{m m})\end{array}$ & $\begin{array}{c}\text { Relative } \\
\text { humidity }(\%)\end{array}$ & $\begin{array}{l}\text { Number of } \\
\text { rainy days }\end{array}$ & $\begin{array}{c}\text { Cumulative amount } \\
\text { of rain }(\mathrm{mm})\end{array}$ & $\begin{array}{l}\text { Adjusted } \\
\qquad R^{2}\end{array}$ \\
\hline \multicolumn{8}{|l|}{ Leaf blotch } \\
\hline 1 & 0.05 & $\ldots$ & $\ldots$ & $\ldots$ & $\ldots$ & $\ldots$ & 0.23 \\
\hline 2 & $\ldots$ & 0.09 & $\ldots$ & 0.02 & $\ldots$ & $\ldots$ & 0.34 \\
\hline 3 & 0.04 & $\ldots$ & $\ldots$ & 0.03 & $\ldots$ & 0.15 & 0.45 \\
\hline \multicolumn{8}{|l|}{ Fruit spot } \\
\hline 1 & 0.06 & $\ldots$ & $\ldots$ & $\ldots$ & $\ldots$ & $\ldots$ & 0.20 \\
\hline 2 & $\ldots$ & 0.03 & 0.06 & $\ldots$ & $\ldots$ & $\ldots$ & 0.32 \\
\hline
\end{tabular}

${ }^{\mathrm{z}}$ Number of factors in model. 
19. Pegg, K. G. 1966. Studies of a strain of Alternaria citri Pierce, the causal organism of brown spot of Emperor mandarin Citrus reticulata. Queensl. J. Agric. Anim. Sci. 23:15-28.

20. Persley, D., and Horlock, C. M. 2009. Apple and pear. Pages 31-32 in: Diseases of Fruit Crops in Australia. T. Cooke, D. Persley and S. House, eds. CSIRO Publishing, Collingwood, Victoria, Australia.

21. Roberts, J. W. 1924. Morphological characters of Alternaria mali Roberts. J. Agric. Res. 27:699-708

22. Rollemberg, C. L., Fayad, F., Hamada, N. A., and De Mio, L. L. M. 2011. First report of Alternaria mali on apples in Brazil. (Abstr.) Phytopathology 101:S155.

23. Rotem, J. 1994. The Genus Alternaria: Biology, Epidemiology, and Pathogenicity. American Phytopathological Society, St. Paul, MN.

24. Rotondo, F., Collina, M., Brunelli, A., and Pryor, B. M. 2012. Comparison of Alternaria spp. collected in Italy from apple with A. mali and other AMtoxin producing strains. Phytopathology 102:1130-1142.

25. Sakuma, T. 1990. Diseases caused by fungi other foliar and fruit diseases Japanese pear black spot Page 25 in: Compendium of Apple and Pear Diseases. A. L. Jones and H. S. Aldwinckle, eds. American Phytopathological Society, St. Paul, MN.

26. Sawamura, K. 1962. Studies on spotted disease of apple 1. Causal agent of Alternaria blotch. Bull. Tohoku Natl. Agric. Exp. Stn. 23:163-175.

27. Sawamura, K. 1972. Studies on apple Alternaria blotch caused by Alternaria mali Roberts. Bull. Fac. Agric. Hirosaki Univ. 18:152-235.

28. Sawamura, K. 1990. Alternaria blotch. Pages 24-25 in: Compendium of Apple and Pear diseases. A. L. Jones and H. S. Aldwinckle, eds. American Phytopathological Society, St. Paul, MN

29. Soleimani, M. J., and Esmailzadeh, M. 2007. First report of Alternaria mali causing apple leaf blotch disease in Iran. Australas. Plant Dis. Notes 2:5758

30. Suzuki, H., Kume, Y., and Matsui, I. 1987. Effect of early defoliation on growth and fruit quality of apple trees. Bull. Akita Fruit-Tree Exp. Stn. 18:1-13.
31. Tanaka, S., Shimomura, S., Takashima, E., Katumoto, K., and Nishi, Y. 1989. Occurrence of fungicide-resistant strains of Alternaria mali in Tokusa Ato-Cho Yamaguchi Prefecture Japan. Bull. Fac. Agric. Yamaguchi Univ. 37:49-60.

32. Thakur, V. S., and Nirupma, S. 2010. Epidemic outbreak of apple blotch disease: epidemiology and management in Himachal Pradesh. Indian Phytopathol. 63:141-144.

33. Thayer, C. L. 2005. Plant Disease forecasting and model validation: classic and modern approaches. Master of Plant Pathology thesis, North Carolina State University, Raleigh.

34. Timmer, L. W., Darhower, H. M., Zitko, S. E., Peever, T. L., Ibanez, A. M., and Bushong, P. M. 2000. Environmental factors affecting the severity of Alternaria brown spot of citrus and their potential use in timing fungicide applications. Plant Dis. 84:638-643.

35. Vicent, A., Badal, J., Asensi, M. J., Sanz, N., Armengol, J., and GarciaJimenez, J. 2004. Laboratory evaluation of citrus cultivars susceptibility and influence of fruit size on Fortune mandarin to infection by Alternaria alternata pv. citri. Eur. J. Plant Pathol. 110:245-251.

36. Wenneker, M., and Vliegen, A. 2012. Spectacular breakthrough in research into premature leaf drop in Golden Delicious. Eur. Fruit Mag. 5:6-7.

37. Wu, G., Wang, Y., Wang, P., Wang, J., and Gong, B. 1999. Study on the differentiation and biological characteristics of Alternaria alternata f. sp. mali. China Fruits 4:11-15.

38. Wunsche, J. N., and Lakso, A. N. 2000. The relationship between leaf area and light interception by spur and extension shoot leaves and apple orchard productivity. HortScience 35:1202-1206.

39. Yin, Y., Bi, Y., Chen, S., Li, Y., Wang, Y., Ge, Y., Ding, B., Li, Y., and Zhang, Z. 2011. Chemical composition and antifungal activity of cuticular wax isolated from Asian pear fruit (cv. Pingguoli). Sci. Hortic. 129:577-582.

40. Yoon, J. T., Lee, J. T., Park, S. D., and Park, D. O. 1989. Effects of meteorological factors on the occurrence of Alternaria leaf blotch caused by Alternaria alternata f. sp. mali. Korean J. Plant Pathol. 5:312-316. 